\title{
The Compressive Strength of Light Weight Concrete
}

\author{
J.E.O. Ovri" and E.O. Okereke
}

*Department of Materials and Metallurgical Engineering, Federal University of Technology, Owerri

(Received 28 July, 2019; accepted 2 January, 2020)

https://doi.org/10.36224/ijes. 120403

\begin{abstract}
The compressive strength of lightweight concrete using palm kernel shell (pks) and periwinkle shell (pws) is reported. The strength as a function of aggregates ,age, and density were investigated. The strengths were measured at interval of 7-day for 28 days. The strengths obtained were in the range of those reported in the standards for lightweight concretes. The densities were also observed to increase with age and fall within the range of those reported in the literature. The results for the compressive strength showed that the strength increases with age for both aggregates.
\end{abstract}

Keywords: lightweight concrete, compressive strengths, palm kernel shell, periwinkle shell, age

\section{Introduction}

Lightweight concrete (LWC) are produced using lightweight coarse aggregates(LWA). The commonly used aggregates are expanded shale, clay or slate materials fired in a rotary kiln to produce a porous structure, air-cooled blast furnace slag [1,2], palm kernel shell (pks) and periwinkle shell (pws) has recently been used as lightweight aggregates [3,5]. Light weight concretes are used in marine and ship building. The use of LWC started in 1914-1918 in the United State of America [6] and their successful use led to the production of USS Selma (a war ship). The durability of this warship was assessed in 1953 and 1980 and little or no corrosion was observed in the waterline area of the ship. Japan [7] has used LWC since 1964 as a rail way station platform. Durability test carried out on LWC in 1983 showed that LWC exhibited similar carbonation depths as normal concrete. Thomas Holm [8] estimated over 400 LWC bridges throughout the world especially in the USA and Canada.

Many agricultural waste materials have been used as lightweight aggregates (LWA) in many developing and under developed countries in Africa and Asia. Some of these materials are palm kernel shells (PKS) and periwinkles (PWS) as lightweight aggregates for lightweight concrete in Malaysia and Nigeria. Abdullah [3] in 1984 was the first to use PKS as LWA in Malaysia and concluded that it is possible to replace normal aggregates with PKS. Okafor [4] in 1988 in Nigeria used PKS and observed that the mechanical properties of the light weight concrete was dependent on concrete mix design, water/concrete ratios and obtained a 28-day compressive strength of 5 to $25 \mathrm{MPa}$. Later researchers, Okpala [5], Olanikpekun et al. [6], Alengaram et al. [8] and Jumaat et al. [9] looked at the physical, mechanical and structural properties of PKS as LWA and showed that pks has similar behaviour as normal aggregate concrete.

Ovri [10] has used palm kernel shells (pks) as LWA to determine the compressive and splitting tensile strengths of concrete and concluded that the workability of the concrete was affected by water/cement ratio. A lower splitting and compressive strengths were obtained than in normal aggregate concrete. Falade et al. [11] looked at the behaviour of LWC containing periwinkle shell (PWS). These low weight materials (pks and PWS) are readily available and affordable by the low income groups in the Niger Delta area of Nigeria. 
Lightweight concrete are classified as structural light weight concrete (ASTM (33082a) [1] - lightweight concrete used in masonry unit, (ASTM C331-81) [1] and insulating concrete (ASTM C332-83) [2].

This specifies the 28- day cylinder compressive strength of not less than $17 \mathrm{MPa}$ with density not less $1840 \mathrm{Kg} / \mathrm{m}^{3(1)}$. Lightweight masonry concrete has a density range of $500-800 \mathrm{~kg} / \mathrm{m}^{3}$ and cylinder compressive strength between $7 \mathrm{Mpa}$ and $14 \mathrm{Mpa}$. Low density lightweight concrete used mainly for insulation purposes rarely exceed $800 \mathrm{~kg} / \mathrm{m}^{3}$ with a cylinder compressive strength of 0.69-6.89 Mpa. Moderate density lightweight concrete lower between structural and low density concrete with a cylinder compressive strength of approximately 6.89 to $17.24 \mathrm{Mpa}$. These have intermediate insulation values. Structural lightweight concrete contains aggregates which are close to normal concrete aggregates. They have minimum cylinder compressive strength of $17.24 \mathrm{MPa}$. There are records of some of these structural concretes that have compressive strengths in excess of $34.47 \mathrm{MPa}$.

The work reported here is a continuation of a study on the characterisation and the mechanical properties evaluation of plain concrete. In particular the effect of aggregates, density, concrete mix design and the curing age of lightweight concrete were considered

\section{Experimental procedure}

\subsection{Aggregates}

\subsubsection{Fine Aggregates}

The fine aggregate (sand) used was obtained from the bed of a river and confirms to ASTM Specification E11 [10,12]. The particle size where those that passed through a sieve with an aperture of $4.75 \mathrm{~mm}$ and was retained on a $0.212 \mathrm{~mm}$ sieve.

\subsubsection{Coarse aggregates}

The coarse aggregates were periwinkle shells (PWS) which were obtained from a stock pile in Yenegoa in Bayelsa State in Nigeria. The particle size were those that passed through a sieve with an aperture of $16 \mathrm{~mm}$ and retained on a $4.75 \mathrm{~mm}$. They were washed to remove all dirts that could impair the strength of the concrete if allowed into the mix. A view of a pack of the periwinkle and a side view is shown in plate 1(a). The palm kernel shells (PKS) were obtained from a palm kernel cracking mill in Umuagwo in Imo State, Nigeria. The sizes of the particle, were those that passed through a sieve with an aperture of $16 \mathrm{~mm}$ and retained on $4.75 \mathrm{~mm}$. The shells with the various particle sizes are shown in plate 1(b).

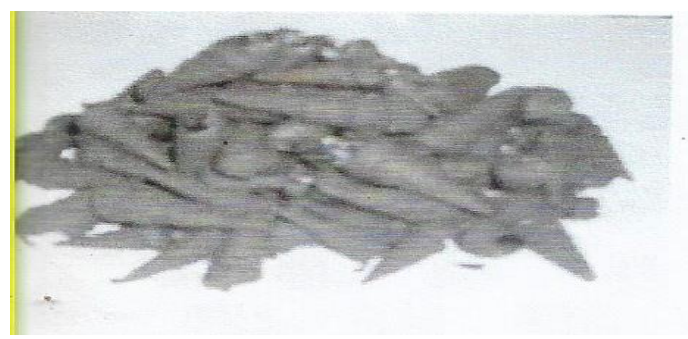

(i)

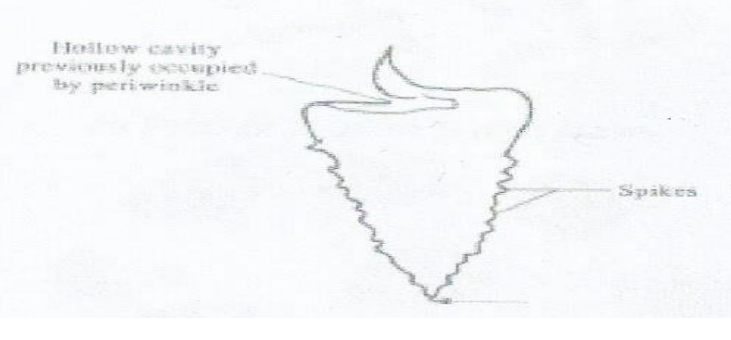

(ii)

Figure 1: (i) Pack of Periwinkle

(ii) Side view of a periwinkle 
a)
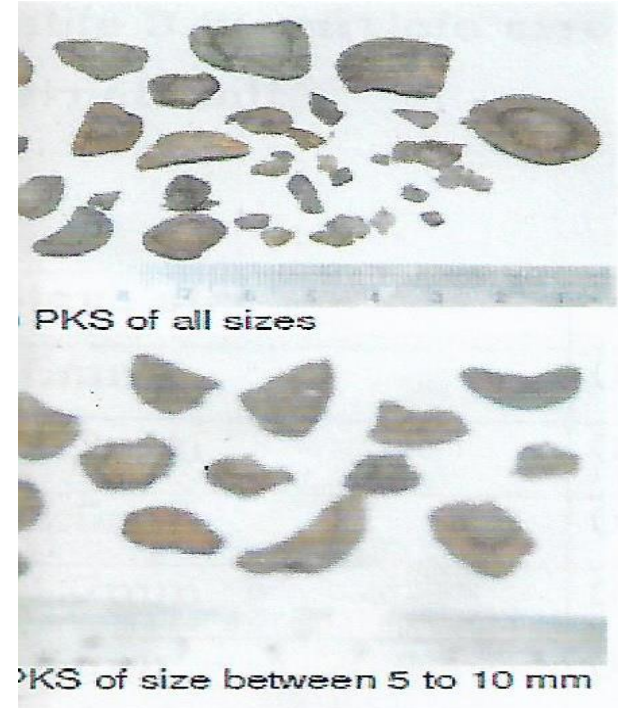

c)

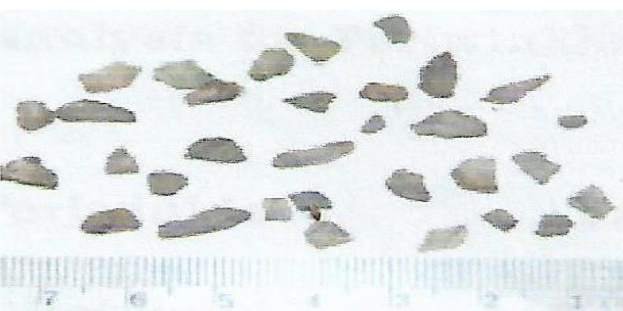

b) PKS of 2.36 to $5 \mathrm{~mm}$ sizes

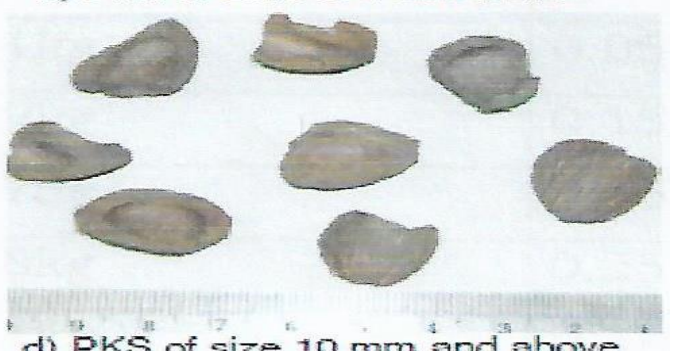

d) PKS of size $10 \mathrm{~mm}$ and above

Figure 2: Palm Kernel Shell of Various Sizes (a) Pks of all sizes (b) Pks of 2.35 to $5 \mathrm{~mm}$ sizes (c) Pks of size between 5 to $10 \mathrm{~mm}$ and (d) Pks of size $10 \mathrm{~mm}$ and above

The particle size analysis are given in Table 1.

Table 1: particle size analysis of the coarse aggregates

\begin{tabular}{|l|l|l|}
\hline Sieve size $(\mathrm{mm})$ & \multicolumn{1}{|c|}{$\begin{array}{c}\text { Periwinkle } \\
\text { (cumulative percentages) }\end{array}$} & $\begin{array}{l}\text { Palm kernel shell } \\
\text { (cumulative percentages) }\end{array}$ \\
\hline 16 & 3.64 & 1.7 \\
\hline 13.2 & 32.73 & 6.9 \\
\hline 12.5 & 27.27 & 12.7 \\
\hline 11.2 & 29.09 & 31.0 \\
\hline 9.5 & 3.64 & 20.7 \\
\hline 4.75 & 3.64 & 31.0 \\
\hline 0 & 100 & 100 \\
\hline Maximum diameter & $16 \mathrm{~mm}$ & $16 \mathrm{~mm}$ \\
\hline & & \\
\hline
\end{tabular}

The cement used was an Ordinary Portland type 1 which $[10,13]$ confirms to ASTM C15080 .

\subsection{Concrete mix design}

Standard mixing modes were adopted [10,3]. Three mix proportions of 1:2:4, 1:21/2:4 and 1:4:4 with water/ cement ratio of 0.45 were used. The mix proportions : 1:2:4 means one part of cement: two parts of fine aggregates and four parts of coarse aggregates, 1: 21/2:4 means one parts of cement :two and half parts of fine aggregates and four parts of coarse aggregates and 1:4:4 means one part of cement: four parts of fine aggregates and four parts of coarse aggregates. The test specimens were moulded according to standard methods $[10,13]$. The cubes were $150 \mathrm{mmx} 150 \mathrm{~mm} \times 150 \mathrm{~mm}$ and were cast in a wooden mould. All the cast specimens were kept in a room at normal temperature for forty-eight hours before demoulding and later returned to the room for curing. Forty specimens were produced, twenty each for each aggregate. 


\subsection{Mechanical Testing}

\subsubsection{Uniaxial compression Test}

The compressive strength of the concrete was determined using a motorised universal compressive testing machine (model $\mathrm{C} 16$ ) at a cross- head speed of $0.2 \mathrm{~mm} / \mathrm{min}[10,13]$. Friction was assumed to be negligible.

\section{Experimental results and discussions}

3.1. Effect of Aggregates on the compressive strength of lightweight concrete

The compressive strength of the concrete was determined using the relation [10]

$$
\sigma_{\mathrm{c}}=\mathrm{P} / \mathrm{A}
$$

$\sigma_{\mathrm{c}}$ is the compressive strength (MPa)

$\mathrm{P}$ is the fracture load $(\mathrm{N})$ and

$\mathrm{A}$ is the specimen cross-sectional area $\left(\mathrm{mm}^{2}\right)$.

The results for the two aggregates are given in Table 2 for the various mixes and displayed in Figure 1.

Table 2: The Compressive Strengths of the Concrete Using Periwinkle and Palm Kerne Shells with Age, Concrete Mix Ratio and Density

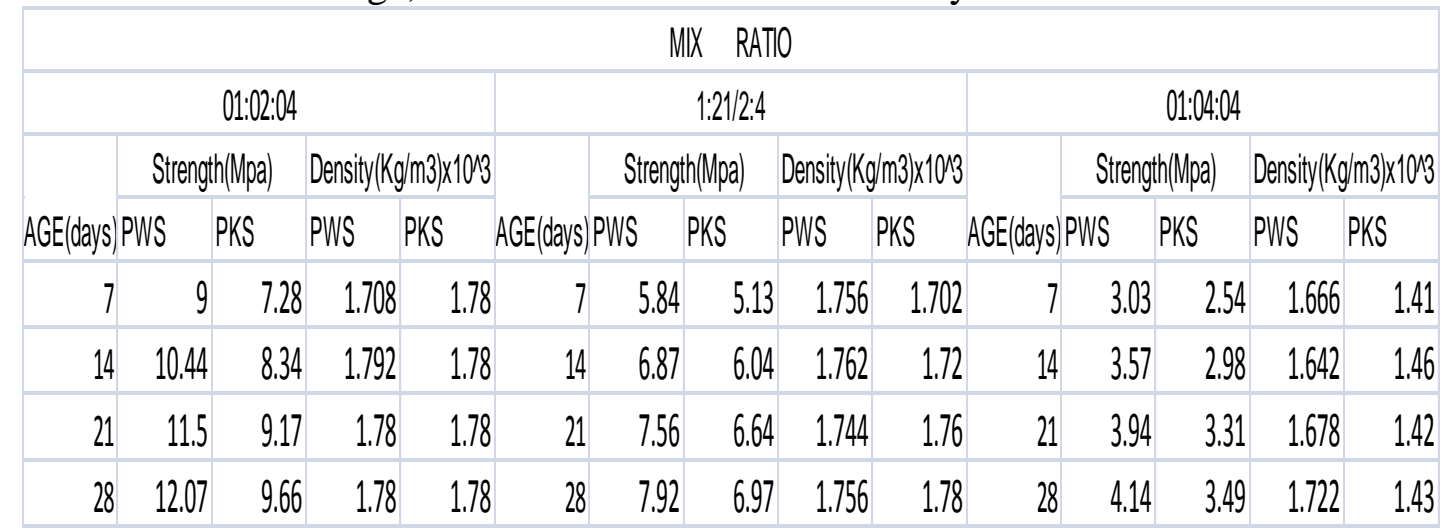

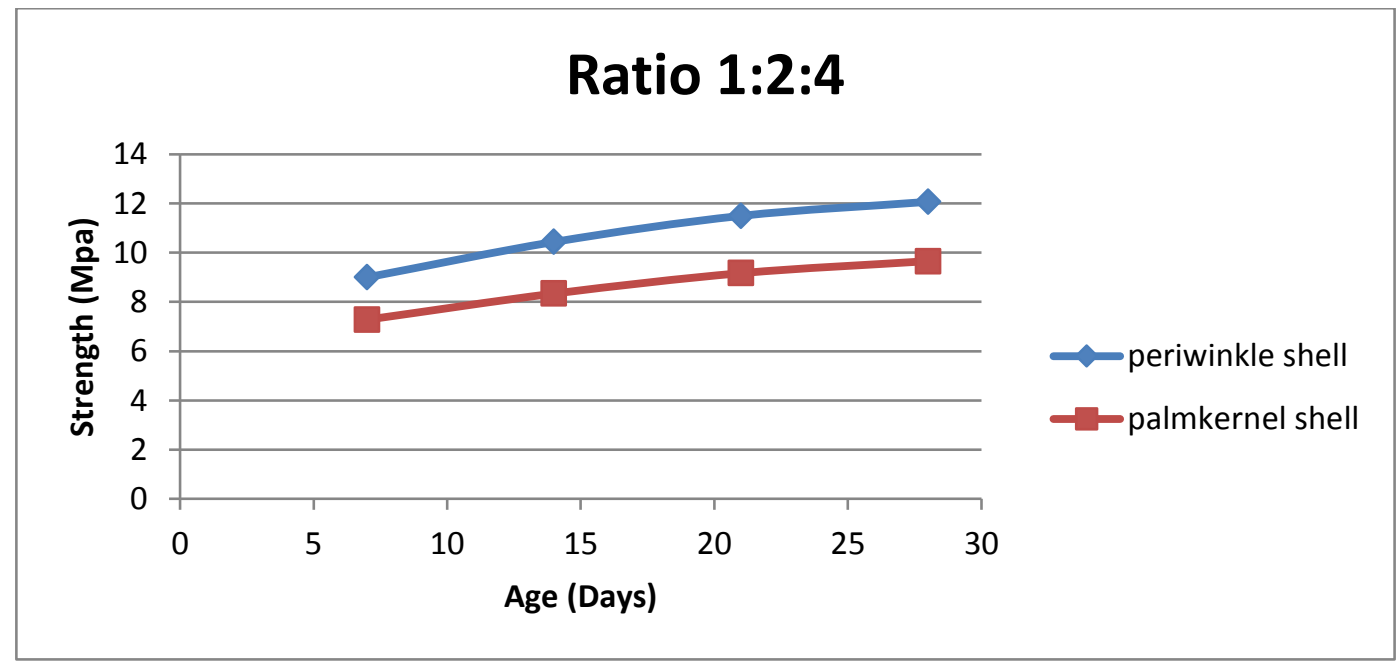

(a) 


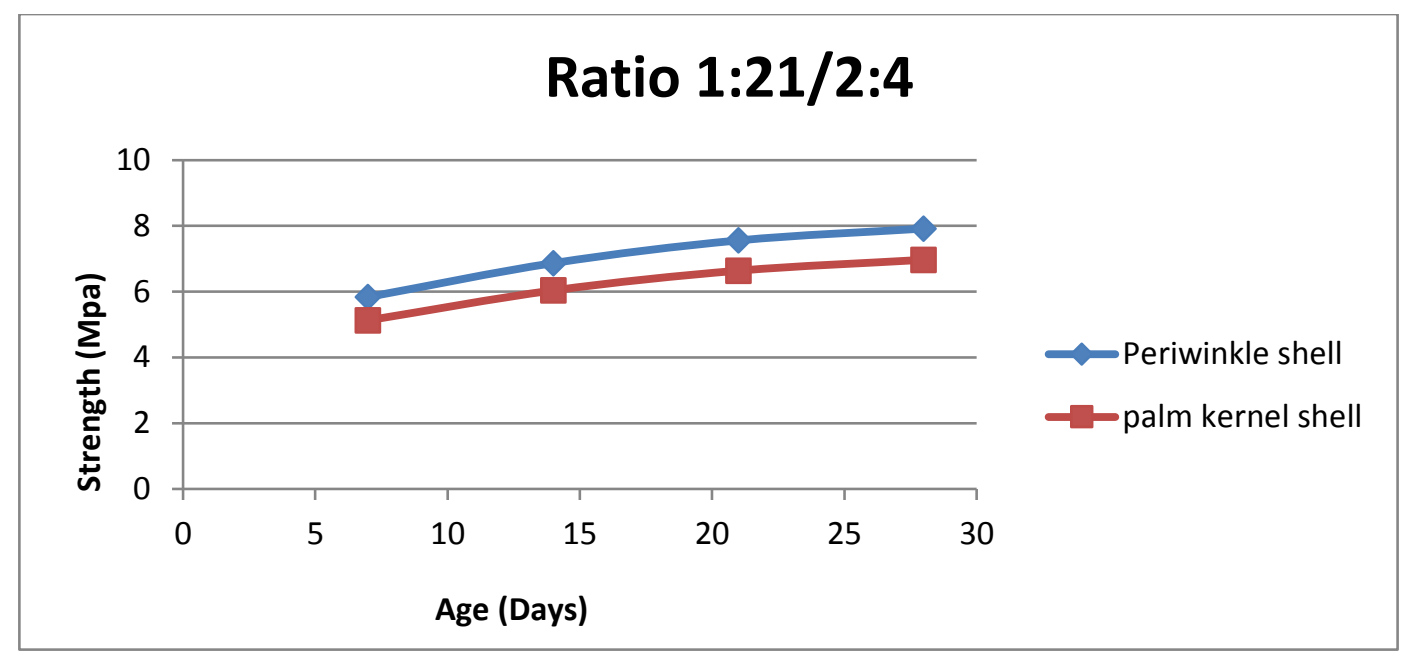

(b)

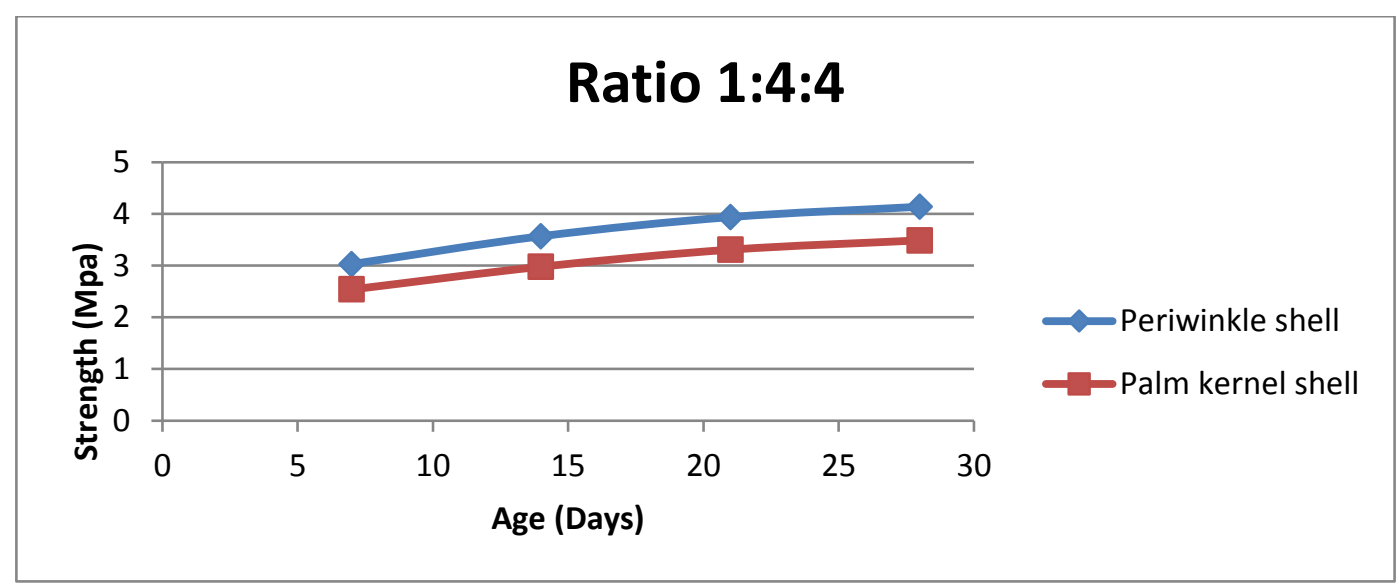

(c)

Figure 3: The Compressive Strength of light Weight Concrete Using Periwinkle and Palm Kernel Shell as a Function of Age (a) 1:2:4 Concrete Mix (b) 1:21/2:4 Concrete Mix and (c) 1:4:4 Concrete Mix

From the Table 2 and Figure 3, it could be seen that higher compressive strengths were obtained for the periwinkle aggregate than the palm kernel shell for all ages and concrete mixes. The increase in the compressive strength was more for the perinwinkle than the palm kernel shells. The 1:2:4 concrete mix has the highest increase in the compressive strength with age for both aggregates with the periwinkle having the higher values. For the 1:21/2:4 mix showed the same trend i.e. higher values for the periwinkle and lower for the palm kernel shell. For the 1:4:4 mix, the strengths are generally lower than the previous mixes. This higher values of the compressive strengths may be due in part to the structure of the aggregates. As the fine aggregates increases the bond between the fine aggregates and the coarse aggregates is reduced and consequently lower compressive strength. These results are in quantitative agreement with previous reports $[10,4]$ the values of the compressive strengths of PKs are in line with those reported by Okafor [4], who had a value of 5 to 25 MPa for 28-day compressive strength. Falade et al. [11] had a range of compressive strength for PWS of 2.85 to $7.35 \mathrm{MPa}$ for $0.6 \mathrm{w} / \mathrm{c}$ ratio light weight concrete. 


\subsection{Bulk density of the concrete}

The bulk density of the concrete were obtained [13] using the weight and physical dimensions of the specimens. The values are given in Table 2 as a function of aggregates, concrete age and concrete mix ratios. It is seen that the bulk densities for the PWS and PKS for the $1: 2: 4$ mix ratio increases from $1.792 \times 10^{3}$ to $1.780 \times 10^{3} \mathrm{~kg} / \mathrm{m}^{3}$ for PWS and $1.780 \times 10^{3}$ to $1.786 \times 10 \mathrm{~kg} / \mathrm{m}^{3}$ for PKS. The PKS densities are essentially constant. These densities are in line with specifications [1] As the mix ratio increases the bulk densities decreased with the 1:4:4 having the lowest bulk densities of $1.4620 \times 10^{3}$ to $1.666 \times 10^{3} \mathrm{~kg} / \mathrm{m}^{3}$. There is no drastic difference with the bulk densities of the 1:2:4 and 1:21/2:4. It could be concluded that there is no much difference in the 1:2:4 and1:21/2:4 mix for both PWS and PKS. However, these bulk densities are within the range of those reported for light weight concrete $[1,11]$.

\subsection{Curing Age}

From Table 2 and Figure 1, it is seen that the compressive strength of the concrete increases with age for both aggregates. This increase is slightly higher for the PWS than the PKS. The increase was observed to depends on the concrete mix. The 1:2:4 had the highest increase followed by the 1:21/2:4 and the 1:4:4. This increase in the compressive strength is due in part to the increased in the hydration of the cement and chemical reactions $[10,13]$.

\section{Conclusion}

The compressive strength of light weight concrete has been investigated using PKS and PWS with the Pws having the highest values in all ages. The compressive strength was found to be dependent on the concrete mix, with the 1:2:4 and 1:21/2:4 mixes giving the most consistent and higher values. The value of bulk densities obtained during the study are within the range reported for lightweight concrete. The compressive strength of lightweight concrete was found to increase with age for periwinkle and palm kernel shells.

\section{References}

1. ASTM Specification C330-82a: American Society for Testing and Materials, Philadephia

2. ASTM Specification C332-83: American Society of Testing and Materials, Philadepia

3. Abdullah, A.A., Basic Strength Properties of lightweight Concrete Using Agricultural Wastes as Aggregates, Procs. Int. Conf. on Low Cost Housing for Developing Countries, Roorkee, India, 1984

4. Okafor, F.O., Palm kernel Shell As Aggregate For Concrete, Cement and Concrete Res.,1988 18(6) $901-990$

5. Okpala, D.C., Palm Kernel Shell As Lightweight Aggregates in Concrete, Building Environment, 1988, 25(4),291-296

6. Olanipekun, E.A., Oluda, K.O. and Ata, O., A Comparative Study of Concrete Properties Using Coconut Shell And Palm Kernel Shell As Coarse Aggregate, Building Environment, 2008, 41(3), 297-301

7. Holm, T.A, and Bremner, T.W., State Of The Report On High Strength, High Durability Structure Low Density Concrete For Applications In Marine Environments, 2000

8. Alengaram, U.J., Jumaat M.Z. and Mahmud, H., Ductility Behaviour Of Reinforced Palm Kernel Shell Concrete Beans" Eur. Journ. Sci. Res., 2008, 23(3),406-420

9. Jumaat, M.Z., Alengaram, U.J. and Mahmud,H. "Shear Strength of Oil Palm Shell Foamed Concrete Beams", Materials and Design,2009, 30(6),2227-2236

10.Ovri, J.E.O. "Effect of Aggregates And Curing Conditions On The Splitting Tensile And Compressive Strengths Of Concrete" Accepted for presentation at $3^{\text {rd }}$ ASRES Congress on Engineering and Applications, Kuala Lumpur, Malaysia,2018, 19-21 
11.Falade, F., IKponmwosa, E.E. and Ojediran "Behaviour Of Lightweight Concrete Containing Perinwinkle Shells At Elevated Temperature” Jour. Eng. Sci. and Techn.,2010,5(4)379-390.

12. ASTM Specification E 11, American Society For Testing and Materials, Philadephia,1982

13. Ovri, J.E.O. “ Determination Of The Mechanical Strength Of Plain Concrete” Glob. Journ. Pure and Appl. Sci.2000,6(2)295-300 